\title{
ANTIBIOSE E NÃO PREFERÊNCIA PARA OVIPOSIÇÃO DE BEMISIA \\ TABACI (GENN.) BIÓTIPO B (HEMIPTERA: ALEYRODIDAE) POR \\ CULTIVARES DE VIGNA UNGUICULATA (L.) WALP.
}

\author{
N.E.L. Rodrigues ${ }^{1}$, A.L. Boiça Júnior ${ }^{2}$, P.R. da S. Farias ${ }^{3}$
}

${ }^{1}$ Universidade Estadual Paulista, Laboratório de Resistência de Plantas, Via de Acesso Prof.Paulo Donato Castellane s/nº, CEP 14884-900, Jaboticabal, SP, Brasil. E-mail: naraelr@hotmail.com

\section{RESUMO}

\begin{abstract}
O objetivo deste trabalho foi identificar cultivares de caupi resistentes a B. tabaci biótipo B e os respectivos tipos de resistência envolvidos. Os experimentos foram conduzidos em casa de vegetação no Departamento de Fitossanidade da Faculdade de Ciências Agrárias e Veterinárias, UNESP/Campus de Jaboticabal, SP, no período de novembro de 2009 a abril de 2010. Realizaramse testes de não preferência para oviposição e antibiose. O delineamento experimental utilizado foi de blocos casualizados para o teste com chance de escolha e inteiramente casualizado para os testes sem chance de escolha e teste de antibiose. Conclui-se que os cultivares BRS Urubuquara, IPA-206 e BR17 Gurgueia apresentaram resistência do tipo não preferência para oviposição da mosca-branca; a cultivar BRS Urubuquara apresenta resistência de tipo antibiose; a cultivar Sempre Verde é suscetível; e, mosca-branca prefere ovipositar na posição superior das plantas.
\end{abstract}

PALAVRAS-CHAVE: Tipos de resistência, mosca-branca, feijão-caupi.

\section{ABSTRACT}

ANTIBIOSIS AND NON-PREFERENCE FOR OVIPOSITION OF BEMISIA TABACI (GENN.) BIOTYPE B (HEMIPTERA: ALEYRODIDAE) OF CULTIVARS OF VIGNA UNGUICULATA (L.) WALP. The objective of this study was to identify cowpea cultivars resistant to $B$. tabaci biotype B and the respective resistance types involved. The experiments were conducted in a greenhouse at the Departamento de Fitossanidade da Faculdade de Ciências Agrárias e Veterinárias, UNESP/ Campus de Jaboticabal, SP, Brasil, from November 2009 to April 2010. Tests for non-preference for oviposition and antibiosis were performed. The experimental design consisted of randomized blocks for the choice test and completely randomized for the no-choice tests and the antibiosis test. It was concluded that the BRS Urubuquara, IPA-206 and BR17 Gurgueia cultivars present non-preference for whitefly oviposition resistance; the BRS Urubuquara cultivar presents nonpreference and antibiosis resistance; the Sempre Verde cultivate is susceptible to oviposition; and the whitefly prefers to deposit eggs on the leaves' abaxial face in the upper position of the plant.

KEY WORDS: Resistance types, silverleaf whitefly, cowpea.

\section{INTRODUÇÃO}

No Brasil, a região Nordeste é a maior produtora e uma das maiores consumidoras de feijão-caupi. Na região Norte destaca-se o Estado do Pará onde, na safra 2007/2008, foram plantados $56 \mathrm{mil}$ ha com feijão-caupi e colhidas 49 mil toneladas, com produtividade média de $870 \mathrm{kgha}^{-1}$ (FILGUeIras et al., 2009).

No entanto, sua produtividade pode ser afetada por fatores bióticos eabióticos, podendo causar danos da semeadura à pós-colheita. Entre as pragas dessa cultura, destaca-se a mosca-branca, Bemisia tabaci
(Genn., 1889) biótipo B (Hemiptera: Aleyrodidae), a qual sob condições favoráveis pode apresentar de 11 a 15 gerações por ano, podendo cada fêmea colocar de 100 a 300 ovos durante o seu ciclo de vida. (BROWN; BIRD, 1992)

Os ovos medem, aproximadamente, $0,2 \mathrm{~mm}$ e a eclosão das ninfas ocorre cerca de cinco dias após a postura. A duração do ciclo de vida da moscabranca varia de acordo com a espécie e condições ambientais, sendo a temperatura um dosfatores mais determinantes. O ciclo de $B$. tabaci dura 19 dias a $32^{\circ}$ C, podendo chegar até 73 dias a $15^{\circ} \mathrm{C}$ (BROwn; BIRD, 1992; SALGUeRO, 1993).

${ }^{2}$ Universidade Estadual Paulista, Departamento de Fitossanidade, Jaboticabal, SP, Brasil.

${ }^{3}$ Universidade Federal Rural da Amazônia, Departamento de Biologia Vegetal e Fitossanidade, Belém, PA, Brasil.

Arq. Inst. Biol., São Paulo, v.79, n.1, p.25-31, jan./mar., 2012 
Na cultura do feijão-caupi, a mosca-branca transmite geminivírus, causador do mosaico dourado; além disso, por meio da sucção contínua de seiva, causa o esgotamento da planta, aparecendo, em consequência, todos os sintomas de uma planta mal nutrida (SILVA, 1997). Esses insetos excretam uma substância açucarada conhecida por honeydew que atrai formigas afugentando seus inimigos naturais além de favorecer o desenvolvimento de fungos de coloração escura, conhecidos por fumagina (SILVA, 1997; LOMBARDI, 2002 citados por Costa et al., 2004).

Nomanejo integrado da mosca-branca devehaver associação de diversas táticas de controle. De acordo com LARA (1991), o uso de cultivares resistentes é sem duvida uma das melhores alternativas para controlar as pragas, por não causar poluição e nem desequilíbrio ecológico, além de permitir harmonia com outras práticas agrícolas. CHu et al. (2001) afirmaram que, para o controle da mosca-branca, o desenvolvimento de plantas resistentes é viável e altamente desejável.

Na cultura do feijão-caupi, Costa et al. (2004), com base no índice de preferência para oviposição, classificaram os cultivares Sempre Verde e Cariri Hilo Preto como estimulantes e o cultivar IPA-206 como inadequado à oviposição de $B$. tabaci biótipo $B$. Dessa forma, o presente trabalho teve por objetivo identificar genótipos de feijão-caupi resistentes a $B$. tabaci biótipo $B$ e os respectivos tipos de resistência envolvidos.

\section{MATERIAL E MÉTODOS}

\section{Criação de manutenção}

A criação de mosca-branca foi realizada em gaiolas com telado tipo anti-afídeo $(2,0 \mathrm{~m}$ de comprimento $\times 3,0 \mathrm{~m}$ de largura $\times 2,0 \mathrm{~m}$ de altura), utilizando-se plantas de couve do cultivar Manteiga Georgia (Brassica oleracea L. var. acephala), mantidas em vasos de 4 L. Para obtenção de altas infestações dessas plantas foram colocados adultos de moscabanca adquiridos de colônias mantidas no setor de Entomologia do Instituto Agronômico de Campinas (IAC). Quinzenalmente, foram introduzidas plantas novas em substituiçãoàs plantas senescentes. Sempre que necessário foram realizados os tratos culturais e irrigação das plantas.

\section{Local de instalação e aspectos gerais}

Os experimentos com B. tabaci biótipo B foram conduzidos em casa de vegetação no Departamento de Fitossanidade da Faculdade de Ciências Agrárias e Vete-rinárias, UNESP/Campus de Jaboticabal, SP, no período de novembro de 2009 a abril de 2010.
Testes de não preferência para oviposição de $B$. tabaci biótipo B com e sem chance de escolha em cultivares de feijão-caupi.

Para a realização dos testes de não preferência para oviposição, foram utilizados sete cultivares de feijão-caupi dispostos em dois experimentos. No primeiro experimento foram avaliados os cultivares BRS Milênio, BR17 Gurguéia, BR3 Tracuateua, BRS Novaera, Sempre Verde, BRS Urubuquara, enquanto no segundo o cultivar BRS Milênio foi substituído pela IPA-206. Nos dois experimento o cultivar Sempre Verde foi adotado como padrão de suscetibilidade e IPA-206 padrão de resistência, com base em Costa et al. (2004). Os demais cultivares utilizados são considerados os mais cultivados e consumidos na região Norte do Brasil. Em ambos os experimentos foram realizados os testes de não preferência para oviposição com e sem chance de escolha.

As plantas foram semeadas em vasos de poliestireno de capacidade de $4 \mathrm{~L}$, utilizando-se um substrato com três partes de terra, uma de areia e uma deesterco. Em cada vaso foram colocadas quatro sementes e, dez dias após a germinação, realizou-se o desbaste, deixando-se apenas uma planta por vaso, sendo irrigadas sempre que necessário.

Notestecom chance deescolha, cada blocofoiconstituído por uma gaiola demetal (1,5 m decomprimento $x 1,5 \mathrm{~m}$ de largura $x 1,8 \mathrm{~m}$ de altura), revestida por tela antiafídeo para proteger as plantas contra infestação de outros insetos. Em cada gaiola foi colocada uma planta de cada cultivar, totalizando seis plantas por gaiola, na qual foram liberados 500 adultos de moscabranca, num total de cinco repetições.

No teste sem chance de escolha, cada cultivar foi individualizado em uma gaiola cilíndrica de metal (60 $\mathrm{cm}$ de altura $\times 40 \mathrm{~cm}$ de diâmetro), revestida por tecido voile, sendo liberados 100 adultos não sexados de mosca-branca por gaiola, adotando-se cinco repetições.

Em ambos os testes, os adultos foram retirados 48 horas após a liberação e anotou-se o número de ovos na face abaxial de todas as folhas das plantas nos terços superior, médio e inferior, com auxílio de um estereoscópico e medida a área foliar através do aparelho LI-COR ${ }^{\circledR}$ modelo 3100, para se calcular o número de ovos por $\mathrm{cm}^{2}$.

Teste de antibiose para $B$. tabaci biótipo $\mathrm{B}$ em cultivares de feijão-caupi

Para o estudo dos aspectos biológicos de $B$. tabaci biótipo $\mathrm{B}$, utilizaram-se cinco plantas com 20 dias de idade dos cultivares IPA-206, BR17 Gurguéia, BR3 Tracuateua, BRS Novaera, Sempre Verde, BRS Urubuquara, obtidas conforme descrito no experimento anterior. Para a obtenção de ovos, 
foram coletados 50 adultos não sexados, da criação de manutenção, com auxílio de um sugador de borracha acoplado em tubo de vidro, os quais foram liberados em gaiolas.

As gaiolas foram feitas com copos plásticos com $4 \mathrm{~cm}$ de diâmetro e $6 \mathrm{~cm}$ de altura, com capacidade para $40 \mathrm{~mL}$, cujo fundo foi retirado. A extremidade maior foi protegida por tecidovoile, ea menor por uma tampa feita com espuma e plástico grosso, fixada na lateral do copo por um grampo (CAMPOs et al., 2009).

Visando evitar a fuga dos insetos, as gaiolas foram rapidamente presas à superfície abaxial das folhas, colocando-se uma gaiola por planta. Decorridas 24 horas, retiraram-se essas gaiolas e os adultos, sendo marcadas as folhas que continham os ovos.

Acompanhou-se diariamente o desenvolvimento da mosca-branca, observando-se a eclosão das ninfas e sua sobrevivência em cada estádio. Foram determinados os seguintes parâmetros biológicos: duração do período ninfal e do período de ovo a adulto e viabilidade da fase ninfal. No último ínstar ninfal as folha foram envolvidas com tecido voile, a fim de se coletar os adultos para avaliação da longevidade. Para isso, dez adultos recém-emergidos de cada cultivar foram coletados eindividualizados em tubos deensaio transparente $(3,6 \mathrm{~mL})$ e mantidos em laboratório, à temperatura de $26 \pm 2^{\circ} \mathrm{C}$, umidade relativa de $70 \pm$ $5 \%$, sem alimentação e fotofase de 12 horas.

\section{Delineamento experimental e análise estatística}

O delineamento experimental utilizado foi de blocos casualizados para o teste com chance de escolha e inteiramente casualizado para os testes sem chance de escolha e teste de antibiose. Nos testes de não preferência para oviposição com chance e sem chance de escolha o delineamento ficou disposto em esquema fatorial $6 \times 3$, representando os cultivares de caupi e os terços da planta, respectivamente, totalizando 18 tratamentos com cinco repetições.

Paraa análise estatística os dadosforam submetidos à análise de variância pelo teste $\mathrm{F}$, sendo as médias comparadas pelotestedeTukey a $\%$ de probabilidade para os testes de não preferência para oviposição, e de, Duncana 5\% deprobabilidade para oteste deantibiose.

\section{RESULTADOS E DISCUSSÃO}

Teste de não preferência para oviposição de $B$. tabaci biótipo B com e sem chance de escolha em cultivares de feijão-caupi

No primeiro experimento no teste com chance de escolha, considerando o número de ovos por $\mathrm{cm}^{2}, \mathrm{o}$ cultivar BRS Urubuquara foi menos preferido para oviposição diferindo significativamente do cultivar
Sempre Verde. No teste sem chance de escolha, o cultivar BRS Urubuquara novamente apresentou menor preferência para oviposição juntamente com o cultivar BR17 Gurgueia diferindo dos cultivares Sempre Verde, BR3 Tracuateua e BRS Milênio. Dessa forma, podendo-se afirmar que o cultivar Sempre Verde apresenta aspectos estimulantes para oviposição, corroborando os dados de COSTA et al. (2004). Por outro lado, o cultivar BRS Urubuquara demonstrou deterrência quanto à oviposição de B. tabaci biótipo $\mathrm{B}$, sugerindo ser inadequada à oviposição do inseto; possivelmente características químicas ou morfológicas (LARA, 1991) desse cultivar atuaram no comportamento do inseto, causando, consequentemente, a não preferência para oviposição em relação à mosca-branca.

Segundo BerLINGER (1986), as características físicas das superfícies foliares, como a pilosidade, a presença de tricomas glandulares aderentes e o formato das folhas, são aspectos que afetam a preferência de oviposição pela mosca-branca. Além disso, a pubescência é um dos fatores que expressa a preferência da mosca-branca para oviposição na superfície inferior das folhas, mas, outras características, como o número de folhas e a área foliar, são também importantes, influenciando essa preferência (SIMMONS, 1994).

Segundo Costa et al. (2004), a não preferência para oviposição pela mosca-branca em cultivares de feijão-caupi, possivelmente, está relacionada ao baixo teor de substâncias atraentes ou aos altos teores de repelentes, que influenciam o comportamento do inseto durante o processo de seleção do hospedeiro.

Com relação à posição das folhas na planta, o terço superior proporcionou maior número de ovos por $\mathrm{cm}^{2}$ (Tabela 1), diferenciando-se da posição basal, onde ocorreu o menor número de ovos, no teste com chance de escolha. Esses resultados coincidem com os obtidos por CAmpos et al. (2005) na cultura de algodoeiro onde o maior número deovos depositados por fêmeas de B. tabaci biótipo B foi observado na folha do ápice, na qual, de acordo com V AN LENTEREN; Noldus (1990), ocorrem maiores teores de nutrientes, os quais podem estar prontamente disponíveis para esses organismos. Folhas mais jovens possuem ainda cutícula fina e macia, além de maior quantidade de água. Essas características, portanto, podem facilitaro processo de oviposição(EICHELKRAUT; CARDONA, 1989) e hidratação dos ovos (GILL, 1990) da mosca-branca.

Para o teste sem chance de escolha, ambas as posições das folhas na planta apresentaram ovos por $\mathrm{cm}^{2}$. Apesar de a posição mediana ter diferido das posições superior e basal, pode-se observar que não foram mantidas as características de não preferência para oviposição na posição basal, as quais, de acordo com LARA (1991), as características responsáveis pela resistência podem não se manter quando isoladas. 
Tabela 1 - Número médio de ovos por $\mathrm{cm}^{2}$ de Bemisia tabaci biótipo B obtidos na face abaxial das folhas, em cultivares de Vigna unguiculata, no primeiro experimento, em testes com e sem chance de escolha. Jaboticabal, SP, 2009.

\begin{tabular}{|c|c|c|}
\hline \multirow[b]{2}{*}{ Cultivar (C) } & \multicolumn{2}{|c|}{ Número de ovos $/ \mathrm{cm}^{2}$} \\
\hline & $\begin{array}{c}\text { Teste com } \\
\text { chance }^{1}\end{array}$ & $\begin{array}{c}\text { Teste sem } \\
\text { chance }^{1}\end{array}$ \\
\hline BRS Urubuquara & $0,48 \mathrm{a}$ & $1,53 \mathrm{a}$ \\
\hline BR3 Tracuateua & $1,60 \mathrm{ab}$ & $5,04 \mathrm{~b}$ \\
\hline BRS Milênio & $1,60 \mathrm{ab}$ & $5,33 \mathrm{~b}$ \\
\hline BR17 Gurgueia & $1,56 \mathrm{ab}$ & $1,19 \mathrm{a}$ \\
\hline BRS Novaera & $1,18 \mathrm{ab}$ & $4,03 \mathrm{ab}$ \\
\hline Sempre Verde & $1,65 \mathrm{~b}$ & $5,50 \mathrm{~b}$ \\
\hline $\mathrm{F}(\mathrm{C})$ & $2,52 *$ & $6,01^{* *}$ \\
\hline \multicolumn{3}{|l|}{ Posição (P) } \\
\hline Superior & $2,53 \mathrm{c}$ & $5,08 \mathrm{~b}$ \\
\hline Mediana & $1,22 \mathrm{~b}$ & $2,09 \mathrm{a}$ \\
\hline Inferior & $0,29 \mathrm{a}$ & $4,14 \mathrm{~b}$ \\
\hline $\mathrm{F}(\mathrm{P})$ & $35,43^{* *}$ & $7,51^{* *}$ \\
\hline $\mathrm{F}(\mathrm{C} \times \mathrm{P})$ & $1,26^{\mathrm{NS}}$ & $0,79^{\mathrm{NS}}$ \\
\hline C.V $(\%)$ & 29,03 & 38,49 \\
\hline
\end{tabular}

${ }^{1}$ Médias seguidas de mesma letra na coluna não diferem estatisticamente entre si pelo teste de Tukey, a 5\% de probabilidade. Para análise, os dados foram transformados em $(x+0,5)^{1 / 2}$

No segundo experimento de não preferência para oviposição, nos testes com chance de escolha, o cultivar Sempre Verde diferiu das demais cultivares avaliadas, corroborando os dados de CosTA et al. (2004) que afirmaram que esse cultivar é suscetível para oviposição de mosca-branca. No teste sem chance de escolha o cultivar BR3 Tracuateua diferiu dos cultivares BR17 Gurgueia e BRS Urubuquara.

Numaanálise geral observa-sequeoscultivares BRS Urubuquara, IPA-206 e BR17 Gurgueia apresentaram as menores médias de número de ovos por $\mathrm{cm}^{2}$ (Tabela 2), demonstrando deterrência quanto à oviposição de B. tabaci biótipo B, ocasionado, possivelmente, por características químicas e/ou morfológicas da planta que atuaram no comportamento da mosca-branca. Sempre Verde novamente apresentou médias de ovos por $\mathrm{cm}^{2}$ altas, confirmando os resultados obtidos por CostA et al. (2004), os quais classificaram esse cultivar como estimulante para oviposição da mosca-branca.

Em relação à preferência para oviposição da mosca-branca quanto à posição das folhas na planta, e considerando a média geral dos tratamentos,
Tabela 2 - Número médio de ovos por $\mathrm{cm}^{2}$ de Bemisia tabaci biótipo B obtidos na face abaxial das folhas, em cultivares de Vigna unguiculata, no segundo experimento, em testes com e sem chance de escolha. Jaboticabal, SP, 2009.

\begin{tabular}{lcc}
\hline \multirow{2}{*}{ Cultivar (C) } & \multicolumn{2}{c}{ Número de ovos por $\mathrm{cm}^{2}$} \\
\cline { 2 - 3 } & $\begin{array}{c}\text { Teste com } \\
\text { chance }\end{array}$ & $\begin{array}{c}\text { Teste sem } \\
\text { chance }^{1}\end{array}$ \\
\hline BRS Urubuquara & $0,18 \mathrm{a}$ & $1,33 \mathrm{a}$ \\
BR3 Tracuateua & $1,28 \mathrm{a}$ & $3,59 \mathrm{~b}$ \\
IPA-206 & $0,23 \mathrm{a}$ & $0,50 \mathrm{a}$ \\
BR17 Gurgueia & $0,30 \mathrm{a}$ & $1,01 \mathrm{a}$ \\
BRS Novaera & $0,50 \mathrm{a}$ & $1,67 \mathrm{ab}$ \\
Sempre Verde & $3,16 \mathrm{~b}$ & $1,53 \mathrm{ab}$ \\
\hline F (C) & $6,30^{* *}$ & $4,12^{* *}$ \\
\hline Posição (P) & & \\
\hline Superior & $2,00 \mathrm{~b}$ & $1,97 \mathrm{~b}$ \\
Mediana & $0,70 \mathrm{a}$ & $2,26 \mathrm{~b}$ \\
Inferior & $0,13 \mathrm{a}$ & $0,57 \mathrm{a}$ \\
F (P) & $12,91^{* *}$ & $8,06^{* *}$ \\
\hline F (C x P) & $3,41^{* *}$ & $1,61^{\mathrm{NS}}$ \\
C.V. $(\%)$ & 41,22 & 40,79 \\
\hline IM Medias & 1,22 &
\end{tabular}

${ }^{1}$ Médias seguidas de mesma letra na coluna não diferem estatisticamente entre si pelo teste de Tukey, a 5\% de probabilidade. Para análise, os dados foram transformados em $(x+0,5)^{1 / 2}$.

ocorreu preferência pelas folhas da região superior (Tabela 2) que correspondiam às folhas mais jovens, corroborando os resultados obtidos por CAMPos et al. (2005), o qual observaram que as folhas localizadas no terço superior apresentaram maior quantidade de ovos por $\mathrm{cm}^{2}$ na cultura do algodoeiro. Na cultura do tomate, ToscANo et al. (2002) também observaram que a praga tem preferência por ovipositar nas folhas mais novas. De acordo com Vendramim et al. (2009), antes de selecionar o local para a oviposição, a moscabranca provavelmente avalia a idade e a qualidade da planta hospedeira por meio da inserção dos estiletes no hospedeiro sem, contudo, ingerir a seiva. Isso provavelmente para encontrar uma constituição química e morfológica mais favorável em razão da idade da planta (WALKER; PERRING, 1994) e dos estímulos envolvidos entre o inseto e a planta (LARA, 1991).

A interação entre cultivares e posição das folhas foi significativa para o cultivar Sempre Verde (Tabela 3), indicando que as folhas superiores desse cultivar apresentam maior atratividade aos adultos da mosca-branca para oviposição.

Tabela 3 - Desdobramento da interação dos cultivares de Vigna unguiculata versus posição das folhas na planta, no segundo experimento, referente ao número médio de ovos por $\mathrm{cm}^{2}$ de Bemisia tabaci biótipo B. Jaboticabal, SP, 2009.

\begin{tabular}{lcccc}
\hline \multirow{2}{*}{ Cultivar $(\mathrm{C})^{1}$} & \multicolumn{3}{c}{ Posição das folhas na planta $^{1}$} & \multirow{2}{*}{$\mathrm{F}(\mathrm{C})$} \\
\cline { 2 - 3 } & Superior & Mediana & Inferior & $0,18^{\mathrm{NS}}$ \\
BRS Urubuquara & $0,29 \mathrm{aA}$ & $0,23 \mathrm{aA}$ & $0,02 \mathrm{aA}$ & $2,33^{\mathrm{NS}}$ \\
BR3 Tracuateua & $1,85 \mathrm{aA}$ & $1,82 \mathrm{aA}$ & $0,18 \mathrm{aA}$ & $0,10^{\mathrm{NS}}$ \\
IPA-206 & $0,33 \mathrm{aA}$ & $0,24 \mathrm{aA}$ & $0,11 \mathrm{aA}$ & $0,23^{\mathrm{NS}}$ \\
BR17 Gurgueia & $0,49 \mathrm{aA}$ & $0,26 \mathrm{aA}$ & $0,17 \mathrm{aA}$ & $1^{\mathrm{NA}}$ \\
BRS Novaera & $1,09 \mathrm{aA}$ & $0,29 \mathrm{aA}$ & $0,11 \mathrm{aA}$ & $25,79^{* *}$ \\
Sempre Verde & $7,93 \mathrm{bB}$ & $1,48 \mathrm{aA}$ & $0,08 \mathrm{aA}$ & 0 \\
F(P) & $12,23^{* *}$ & $0,83^{\mathrm{NS}}$ & $0,66^{\mathrm{NS}}$ & - \\
\hline
\end{tabular}

${ }^{1}$ Médias seguidas da mesma letra, minúscula na coluna e maiúscula na linha, não diferem estatisticamente entre si pelo teste de Tukey, a 5\% de probabilidade. Para análise, os dados foram transformados em $(x+0,5)^{1 / 2}$. 
Tabela 4 - Períodos médio (dias) de incubação, ninfal e longevidade de adultos e viabilidade ninfal de Bemisia tabaci biótipo B obtidos em cultivares de Vigna unguiculata, em casa de vegetação. Jaboticabal, SP, 2010.

\begin{tabular}{lcccc}
\hline Cultivar $(\mathrm{C})$ & $\begin{array}{c}\text { Período de incubação } \\
(\text { dias })^{1}\end{array}$ & $\begin{array}{c}\text { Período ninfal } \\
(\text { dias })^{1}\end{array}$ & $\begin{array}{c}\text { Viabilidade ninfal } \\
(\%)^{2}\end{array}$ & $\begin{array}{c}\text { Longevidade de } \\
\text { adulto (dias) }\end{array}$ \\
\hline BRSUrubuquara & $6,73 \mathrm{~b}$ & $15,76 \mathrm{~b}$ & $52,50 \mathrm{a}$ & $1,13 \mathrm{a}$ \\
BR3 Tracuateua & $5,58 \mathrm{a}$ & $12,99 \mathrm{ab}$ & $50,00 \mathrm{a}$ & $1,16 \mathrm{a}$ \\
IPA-206 & $6,25 \mathrm{ab}$ & $13,29 \mathrm{ab}$ & $52,50 \mathrm{a}$ & $1,00 \mathrm{a}$ \\
BR17 Gurgueia & $6,15 \mathrm{ab}$ & $13,55 \mathrm{ab}$ & $60,00 \mathrm{a}$ & $1,20 \mathrm{a}$ \\
BRS Novaera & $5,53 \mathrm{a}$ & $12,86 \mathrm{ab}$ & $87,50 \mathrm{a}$ & $1,19 \mathrm{a}$ \\
Sempre Verde & $5,78 \mathrm{a}$ & $10,27 \mathrm{a}$ & $90,00 \mathrm{a}$ & $1,22 \mathrm{a}$ \\
\hline F $($ C) & $2,69^{*}$ & $1,83^{\mathrm{NS}}$ & $1,62^{\mathrm{NS}}$ & $1,20^{\mathrm{NS}}$ \\
C.V. $(\%)$ & 9,39 & 19,74 & 36,47 & 12,80 \\
\hline
\end{tabular}

${ }^{1}$ Médias seguidas de mesma letra na coluna não diferem estatisticamente entre si pelo teste de Ducan, a $5 \%$ de probabilidade ${ }^{2}$ Para análise os dados foram transformados em arcsen $[(x+0,5) / 100]^{1 / 2}$

Com relação ao efeito dos cultivares dentro das posições, constatam-se diferenças significativas apenas na posição superior, onde o cultivar Sempre Verde foi o mais preferido para oviposição em relação aos demais, com menores números de ovos por $\mathrm{cm}^{2}$ (Tabela 3). Esse dado é semelhante aos observado por Costa et al. (2004) para o cultivar Sempre Verde, quando testado com outros cultivares.

Teste de antibiose em B. tabaci biótipo B criados em cultivares de feijão-caupi

O período médio de incubação dos ovos de $B$. tabaci nos cultivares de feijão-caupi variou num intervalo de 5,53 a 6,73 dias (Tabela 4), corroborando os dados obtidos por BALDIN et al. (2005) em genótipos de tomateiro e por LIMA; LARA (2004) na cultura da soja, na qual o período de incubação durou cerca de 6 dias em tomateiro e 6,4 a 6,6 dias na cultura de soja. As maiores médias médias observadas ocorreram no cultivar BRS Urubuquara o qual diferiu dos cultivares BRS Novaera, BR3 Tracuateua e Sempre Verde (Tabela 4). Essa diferença ocorre de acordo com BYRNE; BELLOWS JUNIOR (1991) devido o ovo poder absorver água e nutrientes da folha através de seu pedúnculo, sendo que o cultivar BRS Urubuquara deve apresentar algum componente indesejável ao desenvolvimento embrionário.

O período ninfal variou, em média, de 10,27 a 15,76 dias, sendo o cultivar BRS Urubuquara o que apresentou a maior média induzindo maior tempo de desenvolvimento, diferindo do cultivar Sempre Verde (Tabela 4). Dados muito próximos de duração da fase ninfal dessa mosca-branca foram encontrados por ORIANI; LARA (2000), que observaram uma duração de 11,0 a 15,4 dias na cultura do feijão comum.

Para a viabilidade ninfal não houve diferenças entre os cultivares de feijão-caupi, embora se observe tendência de menores médias para os cultivares BR3 Tracuateua, BRS Urubuquara, IPA-206 e BR17 Gurgueia, quando comparadas ao cultivar Sempre Verde, que apresentou 90,00\% em média para essa viabilidade(Tabela 4). Dessa forma, considerando-se todos os parâmetros avaliados, pode-se afirmar queo cultivar Sempre Verde é o mais adequado para o desenvolvimento da mosca-branca. Esses dados ainda sugerem que BRSUrubuquara eIPA-206 apresentam a expressão de não preferência para alimentação e/ ou antibiose o que, de acordo com LARA (1991), faz com que as ninfas necessitem de mais tempo para completar o estágio imaturo, comparativamente a um material suscetível.

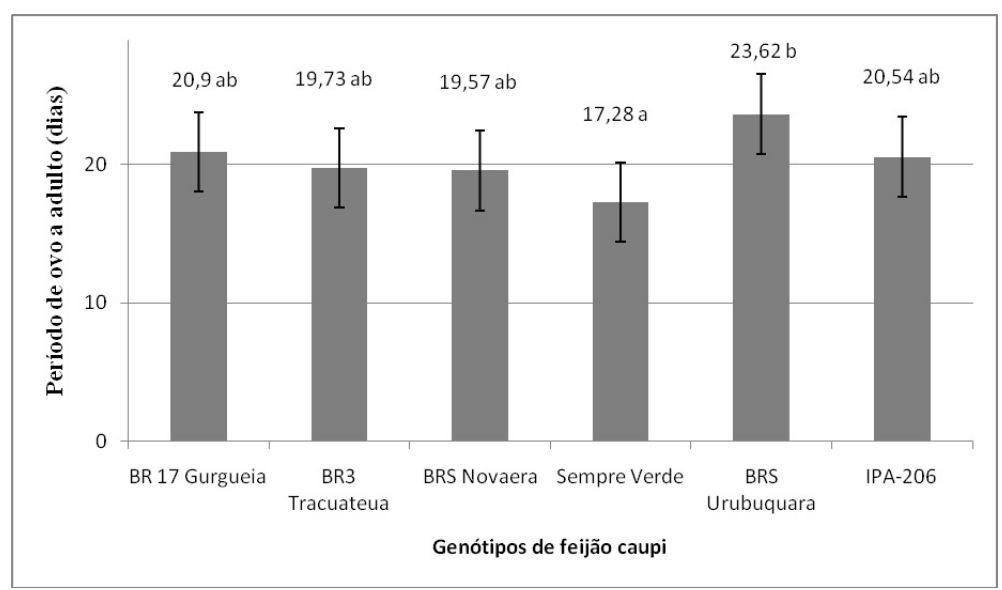

Fig. 1 - Período (dias) de ovo a adulto de Bemisia tabaci biótipo B, obtidos em cultivares de Vigna unguiculata. Jaboticabal, SP, 2010. 
Com relação à longevidade média dos adultos sem alimentação provenientes dos diferentes cultivares de feijão-caupi (Tabela 4), observou-se que os cultivares analisados não diferiram entre si. Esse resultado corrobora os obtidos por BALDIN et al. (2005) em cultivares de tomateiro, que constataram longevidades médias entre 1,1 e 1,3 dias sem alimento, valores muito próximos aos obtidos na presente pesquisa.

Para o período (dias) de ovo a adulto (Fig. 1), foram verificadas diferenças estatísticas entre os cultivares BRS Urubuquara e Sempre Verde, sendo que a maior média (23,62 dias) foi constatada no primeiro e a menor no segundo (17,28 dias). Esses valores são próximos daqueles encontrados por ORIANI; LARA (2000) na cultura do feijão comum em época chuvosa.

\section{CONCLUSÕES}

Os cultivares BRS Urubuquara, IPA-206 e BR17 Gurgueia apresentam resistência do tipo não preferência para oviposição de $B$. tabaci biótipo B;

Ocultivar BRSUrubuquara apresenta resistência a B. tabaci biótipo B do tipo antibiose;

O cultivar Sempre Verde é o mais suscetível à mosca-branca;

B. tabaci biótipo B prefere ovipositar na face abaxial das folhas na posição superior da planta de V. unguiculata.

\section{REFERÊNCIAS}

BALDIN, E.L.L.; VENDRAMIM, J.D.; LOURENÇÃO, A.L. Resistência de genótipos de tomateiro à mosca-branca Bemisia tabaci (Gennadius) biótipo B (Hemiptera: Aleyrodidae). Neotropical Entomology, v.34, n.3, p.435441, 2005.

BERLINGER, M.J. Host plant resistance to Bemisia tabaci. Agriculture, Ecosystems and Environment, v.17, n.1/2, p.69-82, 1986.

BROWN, J.K.; BIRD, J. Whitefly transmited geminiviruses and associated disorders in the Americas and the Caribean Basin. Plant Disease, v.76, n.3, p.220-225, 1992.

BYRNE, D.N.; BELLOWS JUNIOR, T.S. Whitefly biology. Annual Review Entomology, v.36, p.431-457, 1991.

CAMPOS, Z.R.; BOIÇA JUNIOR, A.L.; LOURENÇÃO, A.L.; CAMPOS, A.R. Fatores que afetam a oviposição de Bemisia tabaci (Genn.) biótipo B (Hemiptera: Aleyrodidae) na cultura algodoeira. Neotropical Entomology, v.34, n.5, p.823-827, 2005.
CAMPOS, Z.R.; BOIÇA JUNIOR, A.L.; LOURENÇÃO, A.L.; CAMPOS, A.R. Parâmetros biológicos de Bemisia tabaci (Genn.) biótipo B (Hemiptera: Aleyrodidae) em genótipos de algodoeiro. Bragantia, v.68, n.4, p.10031007, 2009.

CHU, C.C.; FREEMAN, T.P.; BUCKNER, J.S.; HENNEBERRY, T.J.; NELSON, D. R.; NATWICK, E. Susceptibility of upland cotton cultivars to Bemisia tabaci biotype B (Homoptera: Aleyrodidae) in relation to leaf age and trichome density. Annals of the Entomological Society of America, v. 94, n.5, p.743-749, 2001.

COSTA, N.P. da; SANTOS, T.M. dos; BOIÇA JUNIOR, A. L. Preferência para oviposição de Bemisia tabaci biótipo-B em genótipos de caupi. Acta Scientiarum, v.26, n.2, p. 227-230, 2004.

EICHELKRAUT, K.; CARDONA, C. Biologia, cria massal y aspectos ecológicos de la mosca blanca Bemisia tabaci (Gennadius) (Homoptera: Aleyrodidae), com plaga del frijol comum. Turrialba, v. 39, n.1, p.55-62, 1989.

EMBRAPA. Centro Nacional de Pesquisa de Solos. Sistema brasileiro de classificação de solos. Brasília, 1999. 412p.

FILGUEIRAS, G.C.; SANTOS, M.A.S.; HOMMA, A.K.O.; REBELLO, F.K.; CRAVO, M.S. Aspectos socioeconômicos. In: ZILLI, J.E.; VILARINHO, A.A.; ALVES, J.M.A. (Ed.). A cultura do feijão-caupi na Amazônia brasileira. Boa Vista: Embrapa Roraima, 2009. p.23-58.

FREIRE FILHO, F.R.; RIBEIRO, V.Q.; ALCÂNTARA, J.P.; BELARMINO FILHO, J.; ROCHA, M.M. BRS Marataoã: nova cultivar de feijão-caupi com grão tipo sempre-verde. Revista Ceres, v.52, n.303, p.771-777, 2005.

GILL, R.J. The morphology of whiteflies. In: GERLING, D. (Ed.). Whitefly: their bionomics, pest status management. Newcastle: Intercept, 1990, p. 13-46.

LARA, F.M. Princípios de resistência de plantas a insetos. 2.ed. São Paulo: Ícone, 1991. 336p.

LIMA, A.C.S.; LARA, F.M. Resistência de genótipos de soja à mosca-branca Bemisia tabaci (Genn.) biótipo $\mathrm{B}$ (Hemiptera: Aleyrodidae). Neotropical Entomology, v.33, n.1, p.71-75, 2004.

LOMBARDI, 2002 apud COSTA et al., 2002.

OLIVEIRA JUNIOR, J.O.L. de; MEDEIROS, R.D. de; SILVA, P.R.V.P.; MOURÃO JUNIOR, M. Técnicas de manejo para o cultivo do caupi em Roraima. Boa Vista: Embrapa, 2002. 18p. (Circular Técnica, 3).

ORIANI, M.A.G.; LARA F.M. Antibiosis Effects of Wild Bean Lines Containing Arcelin on Bemisia tabaci (Genn.) Biotype B (Homoptera: Aleyrodidae). Anais da Sociedade Entomológica do Brasil, v.29, n.3, p.573-582, 2000. 
SALGUERO, V. Perspectivas para el manejo del complejo mosca blanca - virosis. In: HILJE, L.; ARBOLEDA, O. (Ed.). Las moscas blancas (Homoptera: Aleyrodidae) en America Central y Caribe. Turrialba: CATIE, 1993. p.20-26. (CATIE. Informe Técnico, 205).

SILVA, 1997 apud COSTA, N.P. da et al., 2004

SIMMONS, A.M. Oviposition on vegetables by Bemisia tabaci (Homoptera: Aleyrodidae): temporal and leaf surface factors. Environmental Entomology, v.23, n.2, p.381-389, 1994.

TOSCANO, L.C.; BOIÇA JUNIOR, A.L.; MARUYAMA, W.I. Fatores que afetam a oviposição de Bemisia tabaci (Genn.) biótipo B (Hemiptera: Aleyrodidae) em tomateiro. Neotropical Entomology, v.31, n.4, p.631-634, 2002.

VAN LENTEREN, J.A; NOLDUS, L.P.J.J. Whitefly-plant relationships: behavioral and ecological aspects. In:
GERLING, D. (Ed.). Whiteflies: their bionomics, pest status and management. Andover: Intercept, 1990. p.47-89.

VENDRAMIM, J.D.; SOUZA, A.P. de; ONGARELLI, M. das G. Comportamento de oviposição da mosca-branca Bemisia tabaci (Genn.) (Hemiptera: Aleyrodidae) biótipo B em tomateiro. Neotropical Entomology, v.38, n.1, p.126132, 2009.

WALKER, G.P.; PERRING, T.M. Feeding and oviposition behavior of whiteflies (Homoptera: Aleyrodidae) interpreted from AC electronic feeding monitor waveforms. Annals of the Entomological Society of American, v.18, p.363-374, 1994.

Recebido em 14/1/11

Aceito em 7/11/11 